\title{
Potential role of micro-predators in determining recruitment into a marine community
}

\author{
Richard W. Osman ${ }^{1}$, Robert B. Whitlatch ${ }^{2}$, Richard J. Malatesta ${ }^{2}$ \\ ${ }^{1}$ Academy of Natural Sciences, Benedict Estuarine Research Laboratory, Benedict, Maryland 20612, USA \\ ${ }^{2}$ Department of Marine Sciences, University of Connecticut, Groton, Connecticut 06340, USA
}

\begin{abstract}
Recruitment rates of marine benthic invertebrates are a function of the number of planktonic larvae settling onto the bottom and mortality among the earliest post-settlement life-stages. Unfortunately, rates of mortality are seldom measured for the time between settlement and recruitment and little is known about the importance of such mortality, its causes, or how it compares to other processes affecting recruitment. In our investigations of a New England, USA, marine community, we found significant predation exclusively on the earliest life-stages of several dominant species. The predators were 2 species of tiny gastropods, Mitrella lunata and Anachis avara. They preyed selectively on newly-settled colonial ascidians, greatly lowering or eliminating recruitment of these species. This brief predation on early life-stages enabled other species to replace the competitively superior ascidians within the developing community.
\end{abstract}

\section{INTRODUCTION}

Species with several distinct life-stages often experience ontogenetic changes in their trophic and competitive relationships with other species (Barker 1979, Menge \& Sutherland 1987, Roughgarden et al. 1988 Osman et al. 1990). These changes can be quite rapid for individuals recruiting into marine benthic communities, making them difficult to observe and measure. Although a few studies (Bernstein \& Jung 1979, Grosberg 1982, Yoshioka 1982, Gaines \& Roughgarden 1987) have shown a correlation between the abundance of planktonic larvae and measured recruitment, interactions that differentially affect early life-stages can greatly alter initial settlement patterns into very different patterns of recruitment (Grosberg 1981, Underwood \& Denley 1984, Wethey 1984, 1986, Caffey 1985, Connell 1985, McGuinness \& Davis 1989, Osman et al. 1989, Stoner 1990).

Thus, if recruitment is important to the development of a community, several factors must be considered (1) the supply of settling larvae (Roughgarden et al 1985, 1988, Gaines \& Roughgarden 1987), (2) densitydependent post-settlement mortality that would tend to nullify any variability resulting from larval settlement (Connell 1985, McGuinness \& Davis 1989), and
(3) species-specific mortality restricted to the earliest life-stages. This mortality would both alter relative abundances prior to the measurement of recruitment and not be predicted from observations of adults. It is the ability of predators preying exclusively on early life-stages to produce such pre-recruitment mortality of particular species that we will address.

In the summers of 1987 to 1990 we conducted a series of small-scale studies in Vineyard Sound, Massachusetts, and Long Island Sound, Connecticut, USA. These studies eventually focused on 2 species of tiny gastropods that seemed to prey exclusively on newly settled individuals of dominant colonial ascidians. The potential of predation to alter the abundances of recruiting ascidians has been suggested by several earlier studies. In studies of North Carolina, USA, fouling communities, Sutherland (1974) found that occasional fish predation on young Styela plicata could remove it as a potential dominant. Young \& Chia (1984) found that in Puget Sound, Washington, USA, the small gastropod Margarites pupillus could significantly reduce the number of newly-settled individuals of the solitary ascidians Corella inflata and Boltenia villosa but not of Styela gibbsi. They suggested that this and other sources of post-settlement mortality, such as overgrowth by algae and sedimentation, con- 
tributed to differences in distribution. In Hawaii, USA, Stoner (1990) followed newly-settled individuals of the colonial ascidian, Diplosoma similis, and found that less than $50 \%$ survived for more than $1 \mathrm{~d}$. He attributed much of this mortality to fish predation. Finally, similar to Sutherland (1974) we found that predation by the wrasse Tautogolabrus adspersus on juvenile solitary ascidians could contribute to their low abundance at 1 of 2 field sites (Osman et al. 1990).

Our preliminary observations indicate that within at least one New England subtidal community, predation by tiny gastropods can also increase the postsettlement mortality of several dominant species. As a consequence, settlement patterns can be changed into very different patterns of recruitment which, in turn, can alter adult communities.

\section{METHODS}

Our initial observations concentrated on the attached invertebrates commonly found on docks and jetties at 2 sites in Woods Hole, Massachusetts. The first, more exposed site was a pier in Vineyard Sound and the second site was a dock in Eel Pond, a protected harbor with a narrow connection to Vineyard Sound (Fig. 1). All dominant species, except one (the bryozoan Bugula stolonifera, found only in Eel Pond), were found at both sites. However, surfaces on pilings at the Vineyard Sound site that were $1 \mathrm{~m}$ below mean low water (MLW) were completely dominated by the bryozoans Schizoporella errata and Bugula turrita while the Eel Pond dock was dominated by the ascidians Botryllus schlosseri, Botrylloides diegensis, and Styela clava. Based on previous studies (Osman 1977. Grosberg 1981) colonial ascidians are dominant competitors for space and should have eventually replaced the bryozoans at the Vineyard Sound site. Nevertheless, the differences between the sites remained stable over 4 summers of observation and were similar to patterns observed in earlier studies (Grave 1933, Osman 1977, Grosberg 1981). It should be noted that the colonial ascidians Botryllus and Botrylloides can be semelparous or iteroparous and their abundances may have declined in the autumn as the result of postreproductive colony mortality.

To examine the relationship of larval settlement to these dominance patterns, settlement and colonization panels were suspended 1 to $2 \mathrm{~m}$ below MLW at both sites and data were collected from the lower, bottomfacing surfaces of the panels. Panels were $100 \mathrm{~cm}^{2}$ in area and constructed of PVC plastic. Two replicate settlcmont pancls wore exposed at each site in 1987 and 1988 using racks similar to those used by Osman (1982). These panels were collected and replaced by clean panels every other day and the numbers of individuals of all species were counted to estimate settlement. In 1987, 8 replicate colonization panels were also exposed at each site. These panels were exposed continuously and were monitored every 1 to 2 wk for

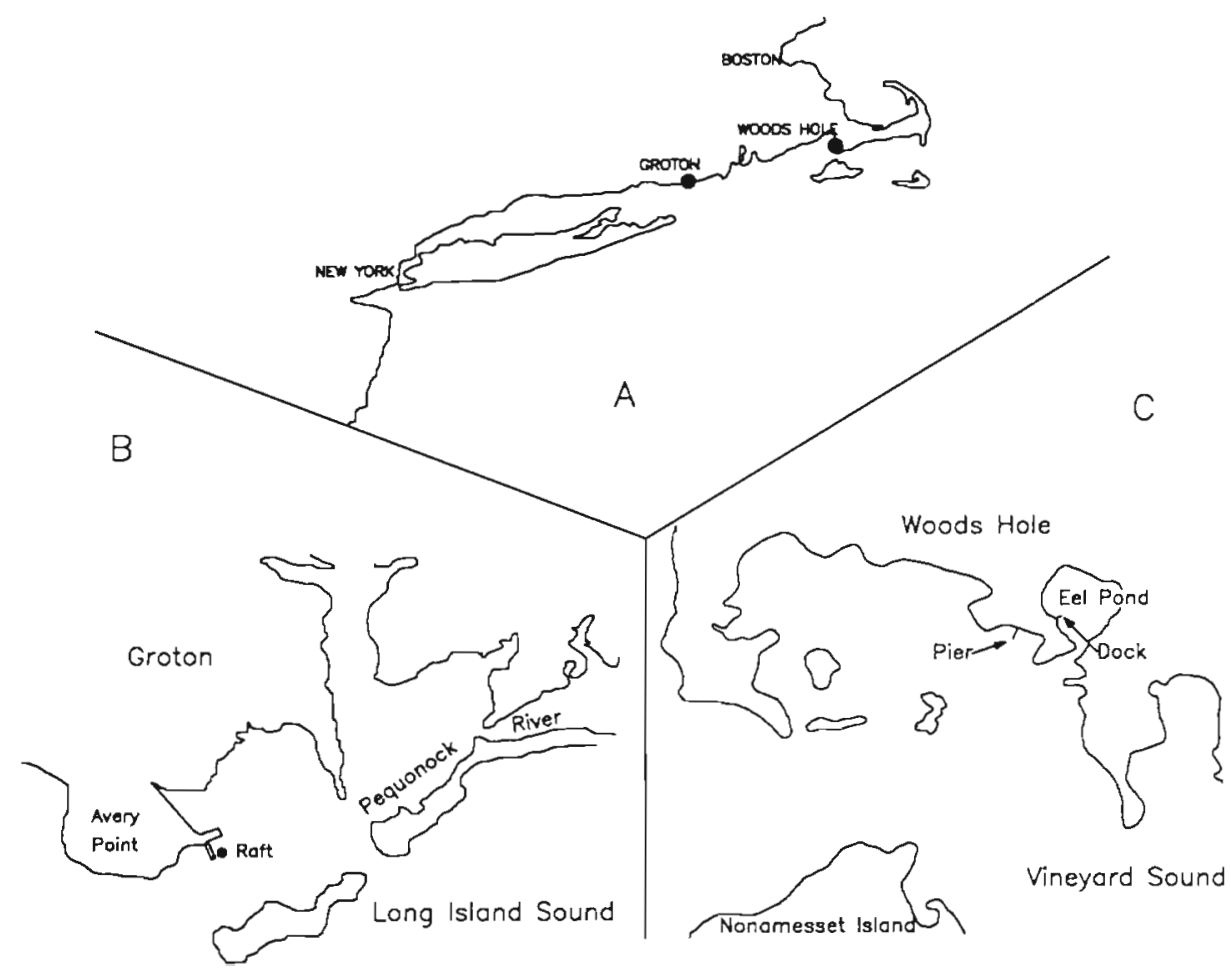

Fig. 1 Study sites in Woods Hole, Massachusetts and Groton., Connecticut, USA 
community development. After 2 wk, 4 panels from each site were reciprocally transplanted between the 2 sites to test whether differences between the 2 sites in larval availability would alter the development of the community. At the time of transfer the majority (70 to $90 \%$ ) of all panel surfaces still remained open and available to settling larvae, but panels from the 2 sites had developed a community of recruits characteristic of that site.

In 1988 a second transplant experiment was conducted with Botryllus schlosseri to test whether increasing its settlement rate at the Vineyard Sound site would change the community that developed. Panels were initially exposed in Eel Pond for $3 \mathrm{~d}$ and then taken to the laboratory. Two density treatments of 40 and $10 \mathrm{~B}$. schlosseri colonies ( 1 to $3 \mathrm{~d}$ old) per panel were established by the removal of all other species followed by a haphazard removal of excess $B$. schlosseri. Four panels of each density treatment were randomly assigned to each of the 2 stations. The panels were sampled and photographed 4 times during the following 3 wk and all colonies were counted and measured. The photographs enabled any newly-settled individuals to be distinguished from those present at the start of the experiment.

Observations made at the Woods Hole sites in 1988 and laboratory studies conducted in 1989 (Osman et al. 1990) suggested that the presence of 2 predatory gastropods, Mitrella lunata and Anachis avara, at the Vineyard Sound site contributed to the low rates of recruitment by colonial ascidians at this site. In 1989 and 1990 we conducted field experiments to measure the effects of both M. lunata and $A$. avara on the recruitment of sessile invertebrates. For logistical reasons these experiments were conducted at Avery Point, Connecticut (Fig. 1). All the dominant species from the 2 Woods Hole sites were found on rocks, jetties, or algae at this site and were collected on recruitment panels exposed for $1 \mathrm{wk}$ periods. Both $M$. lunata and $A$. avara are present in the Groton area (respective mean densities of 0.88 and 0.78 ind $100 \mathrm{~cm}^{-2}$ on rocks at a collection site $8 \mathrm{~km}$ west of our raft at Avery Point), but were rare or absent at the study site. Ascidians rather than bryozoans were the dominant epifauna. Experiments were conducted with A. avara in 1989 and 1990 and with $M$. lunata in 1990 . In interpreting the results, we assumed that the feeding behavior and prey preferences were the same as in Woods Hole.

In each experiment, 10 replicate $2.5 \times 7.5 \times 9 \mathrm{~cm}$ cages were each partitioned into 2 equal chambers using a $7.5 \times 2.5 \mathrm{~cm}$ panel (Fig. 2). Cages were constructed using plastic slide boxes. Holes were drilled in the walls of the boxes to allow water exchange but prevent either gastropod species from escaping. A single snail was placed in 1 chamber (equivalent to a density of 0.78 ind. $100 \mathrm{~cm}^{-2}$, including the cage walls) and this exposed 1 surface of the central panel to the predator while keeping the paired, opposite surface predator-free. Because the cages also restricted recruitment, 2 sets of panels were used. While substrates from 1 set were inside the cage, substrates from the second set were held outside of the cage. When outside of the cage, panels were held in a vertical orientation with both sides exposed equally to settling larvae. Every day the 2 sets of panels were switched. thus allowing unrestricted recruitment on alternate days. Rarely, a snail died during an experiment. If this occurred then the gastropod was replaced by a new starved individual.

Cages were suspended at a depth of $1 \mathrm{~m}$ below a raft moored in $4 \mathrm{~m}$ of water. All but 1 experiment ran for $8 \mathrm{~d}$ (the second 1990 Anachis avara experiment ran 14 d) after which time panels were sampled and a new experiment was begun with new panels and new, starved snails. All individuals or colonies of all species were counted on both the control and treatment surfaces of each panel. The $A$. avara experiment was conducted once in August 1989 and during 7 consecutive time periods from 27 June to 25 August 1990. The Mitrella lunata experiment was repeated during 3 consecutive time periods from 21 August to 11 September 1990.

During the course of the study recruitment rates of most species varied greatly resulting in each experiment being conducted under different, uncontrolled conditions. Therefore, the recruitment rate of each of the most abundant species was analyzed separately for each of the 11 experiments. We did not adjust the significance level of any statistical test to account for possible Type I error associated with the large number of analyses. However, we did ignore any effects of marginal significance that were confined to a single experiment.

The experiments were designed to use the difference between treatment and control surfaces of each panel as an estimate of the effect of the predator. However, this design neglected to account for the

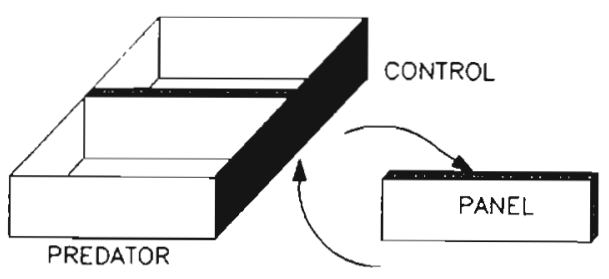

Fig. 2. Design for caging experiments. Panel inside the cage divides it into predator and control cells. A second panel is outside the cage in order to allow settlement. Inside and outside panels were switched every day. The difference in a species abundance between the 2 surfaces of each panel was used to measure the effect of the predator 
possible effect of each cage on the 2 panels that shared it (and the same snail) on alternate days. Therefore, we analyzed for this cage effect using a 1-way analysis of variance to test for differences among cages in the difference between predator and control surfaces. Only 3 of the 66 analyses $(6$ recruiting species $\times 11$ experiments) exhibited any significant differences among cages. All 3 were for Diplosoma sp. in the 1990 Anachis avara experiments at times when strong predator effects were found. In all cases the significant difference among cages appeared to have resulted from the lack of a strong predator effect on both panels using 1 of the 10 cages (possibly from a non-feeding, satiated, or undetected dead snail). Based on the general lack of cage effects, data from both series of panels were pooled for the paired $t$-tests.

Finally, a colonization experiment was run concurrently with the 1990 Anachis avara experiments. This experiment was conducted exactly as the recruitment experiments, except that panels were not replaced by new clean panels. This allowed the community to develop through the cumulative recruitment and growth of species. Abundances of all species were estimated using a grid of evenly spaced points placed haphazardly over each panel. Approximately 150 points were counted for each panel.

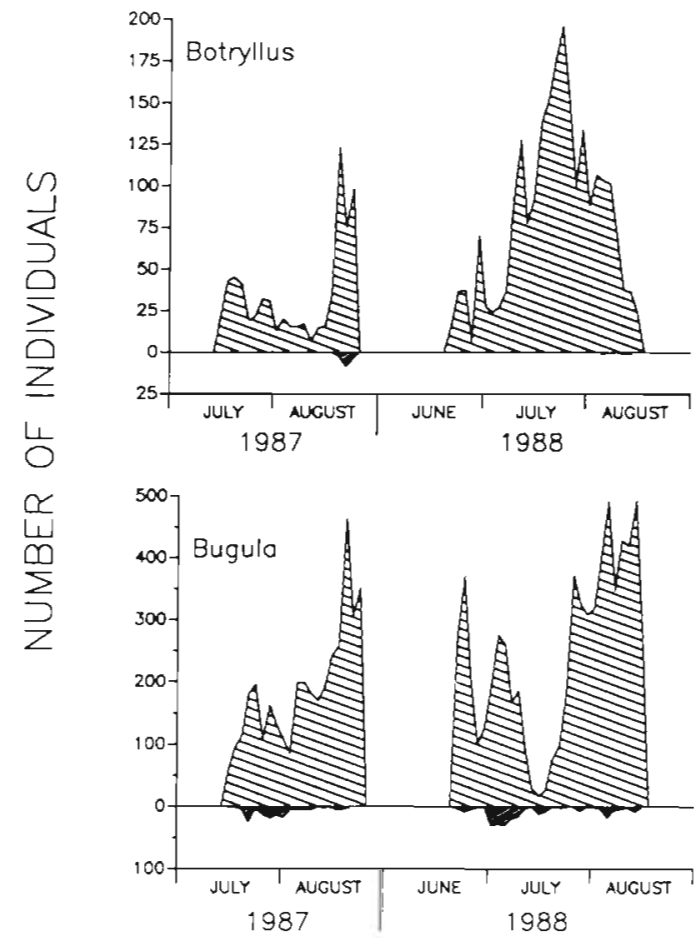

\section{RESULTS}

\section{Settlement and community development}

Within each of the 2 Woods Hole sites both larval settlement and community development correlated well with the patterns of adult distribution. Except for Schizoporella errata in 1987, larval settlement was 10 to 100 times higher in Eel Pond than in Vineyard Sound (Fig. 3). With the apparent absence of ascidian settlement, the bryozoans Schizoporella errata and Bugula turrita dominated settlement in Vineyard Sound. In Eel Pond Bugula spp. and ascidians dominated settlement. However, it should be noted that Bugula settlement in Eel Pond included both $B$. turrita and $B$. stolonifera. We could not differentiate between newly-settled individuals of these species.

After 2 mo the continuously exposed colonization panels in Vineyard Sound had no ascidian species and were completely dominated by Schizoporella errata and Bugula turrita (Fig. 4). Conversely, ascidians along with Bugula stolonifera dominated the Eel Pond colonization panels. Although some differences were seen in the transplant panels, they remained most similar to the panels that remained at their site of origin (Fig. 4), Vineyard Sound panels moved to Eel Pond were colo-
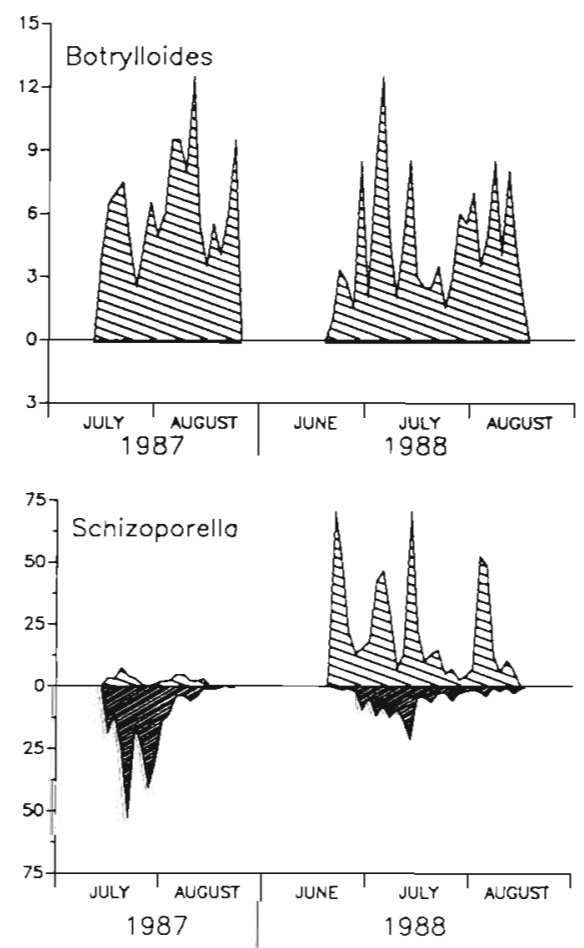

Fig. 3. Botryllus schlossen, Botrylloides diegensis, Bugula spp., Schizoporella errata. Comparison of the mean settlement of the 4 dominant species in Eel Pond (upper part of each graph) and Vineyard Sound (lower part of each graph). Settlement was measured in sequential $2 \mathrm{~d}$ periods over the 2 time periods shown. Mean settlement rate for Botrylloides diegensis in Vineyard Sound was never more than 0.5 ind, in any sampling period 

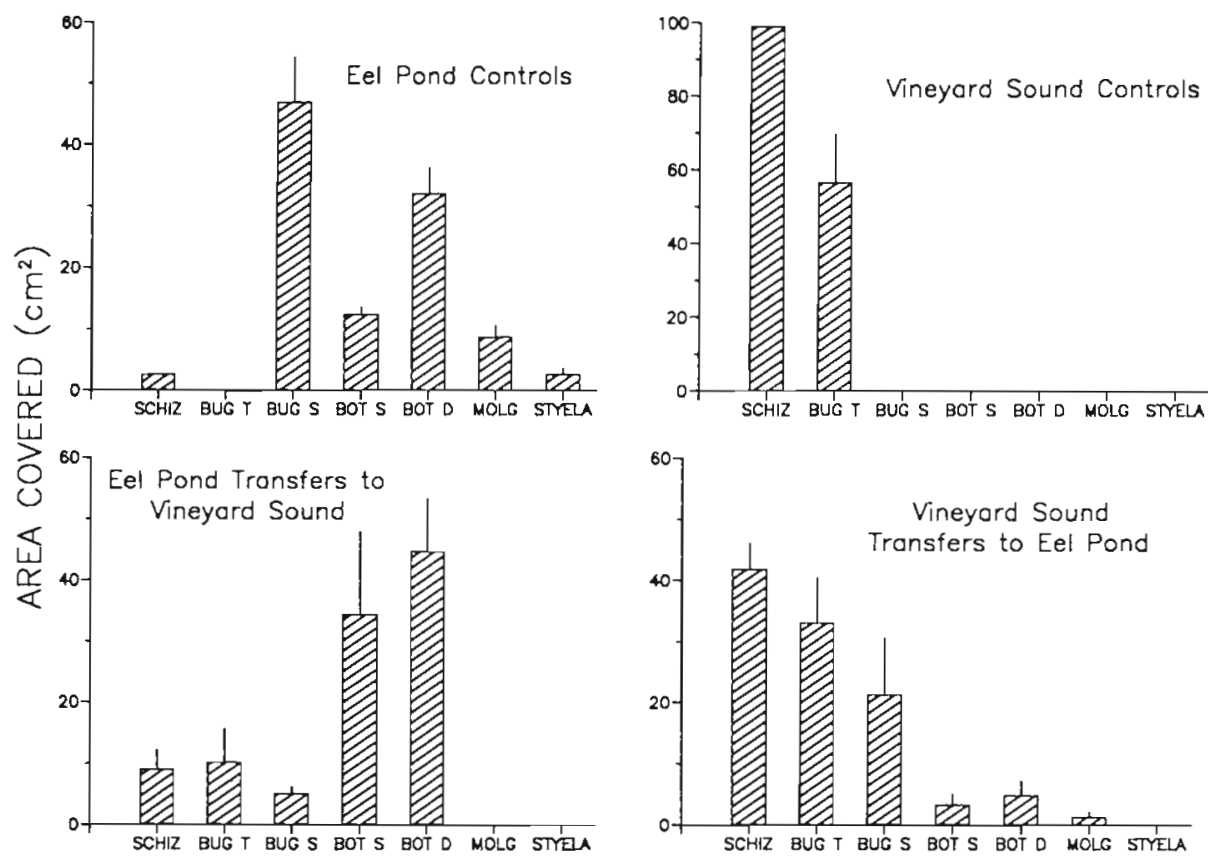

SPECIES

Fig. 4. Comparison of the mean abundance of the dominant species on colonization panels exposed in Eel Pond and Vineyard Sound as well as panels transplanted between the 2 sites $2 \mathrm{wk}$ after they were initially exposed. Measurements were made at the end of the summer after 2 mo of exposure. Cumulative area covered by all species usually exceeded the $100 \mathrm{~cm}^{2}$ available on each panel because the Bugula spp. canopy as well as the species underneath were measured. Abundances of encrusting species on the Eel Pond control panels and the Vineyard Sound panels transferred to Eel Pond were somewhat underestimated because not all substrate under the $B$. stolonifera canopy could be measured from photographs. SCHIZ: Schizoporella errata; BUG T: Bugula turrita; BUG S: Bugula stolonifera; BOT S: Botryllus schlosseri; BOT D: Botrylloides diegensis; MOLG: Molgula manhattensis; STYELA: Styela clava

nized by ascidians and $B$. stolonifera, but the panels became dominated by those bryozoans dominating the control Vineyard Sound panels. Eel Pond panels transplanted to Vineyard Sound had no solitary ascidians but were dominated by colonial ascidians. Fish predation (Osman et al. 1990) probably accounted for the lack of solitary ascidians and, perhaps, associated $B$. stolonifera. Finally, measurements of colonies on all 4 sets of panels indicate that environmental conditions at the 2 sites did not have a negative effect on the growth rates of transplanted species. Botrylloides diegensis grew faster when transplanted from Eel Pond to Vineyard Sound, while the other species examined displayed no differences between sites (Table 1). Thus, from these data, it appears that unmeasured differences in the physical environment resulting in disparate growth and survival contributed little to the drastically different dominance patterns seen at the 2 sites. The observed variation is most easily explained as a consequence of differences in the relative abundance of settling larvae, possibly coupled with predation on any newly-settled solitary ascidians at the Vineyard Sound site.
Results of the 1988 Botryllus schlosseri transplant experiment were not as we expected based on the 1987 experiments. After 3 wk 58 and $100 \%$ of the colonies at the Eel Pond site survived on the high- and low-density treatments (Fig. 5). However, only 1 of the 200 B. schlosseri colonies transplanted to Vineyard Sound survived more than 2 d. By closely observing the panels from the Vineyard Sound site in the laboratory, we found 2 species of small (1 to $10 \mathrm{~mm}$ shell length) gastropods, Mitrella lunata and Anachis avara, which preyed extensively on newly-settled B. schlosseri and Botrylloides diegensis but not on older juvenile (such as those transplanted in 1987) or adult colonies. These observations were confirmed by laboratory feeding experiments in which neither of the predators preyed on $B$. schlosseri or $B$. diegensis colonies larger than 5 zooids while consuming almost all B. schlosseri colonies less than 5 zooids (Osman et al. 1990). High juvenile and low adult mortalities both inside and outside of field cages which excluded larger predators, but not $M$. lunata or $A$. avara, also suggested snail rather than fish predation on juveniles (Osman et al. 1990). 
Table 1. Comparison of colony sizes (in $\mathrm{Cm}^{2}$ ) of the 4 dominant species at the 2 field sites. Bryozoans were transplanted from Vineyard Sound to Eel Pond and ascidians were transplanted from Eel Pond to Vineyard Sound. Data analyzed using ANOVA with colonies nested by panel and Bonferroni a posteriori tests

\begin{tabular}{|c|c|c|c|c|}
\hline Treatment & Week & $\mathrm{n}$ & Mean & Group \\
\hline \multicolumn{5}{|l|}{ Schizoporella errata } \\
\hline Vineyard Sound & 2 & 313 & 0.51 & \\
\hline Transfer to Eel Pond & 2 & 286 & 0.41 & \\
\hline Vineyard Sound & 1 & 402 & 0.17 & \\
\hline Transfer to Eel Pond & 1 & 421 & 0.09 & \\
\hline \multicolumn{5}{|l|}{ Bugula spp. } \\
\hline Vineyard Sound & 2 & 338 & 0.15 & \\
\hline Transfer to Eel Pond & 2 & 286 & 0.14 & \\
\hline Vineyard Sound & 1 & 380 & 0.04 & \\
\hline Transfer to Eel Pond & 1 & 323 & 0.03 & \\
\hline \multicolumn{5}{|l|}{ Botryllus schlosseri } \\
\hline Transfer to Vineyard Sound & 2 & 95 & 0.54 & \\
\hline Eel Pond & 2 & 136 & 0.32 & \\
\hline Eel Pond & 1 & 154 & 0.30 & \\
\hline Transfer to Vineyard Sound & 1 & 116 & 0.22 & \\
\hline \multicolumn{5}{|l|}{ Botrylloides diegensis } \\
\hline Transfer to Vineyard Sound & 2 & 38 & 3.24 & । \\
\hline Transfer to Vineyard Sound & 1 & 60 & 0.93 & \\
\hline Eel Pond & 2 & 101 & 0.62 & \\
\hline Eel Pond & 1 & 106 & 0.35 & \\
\hline
\end{tabular}

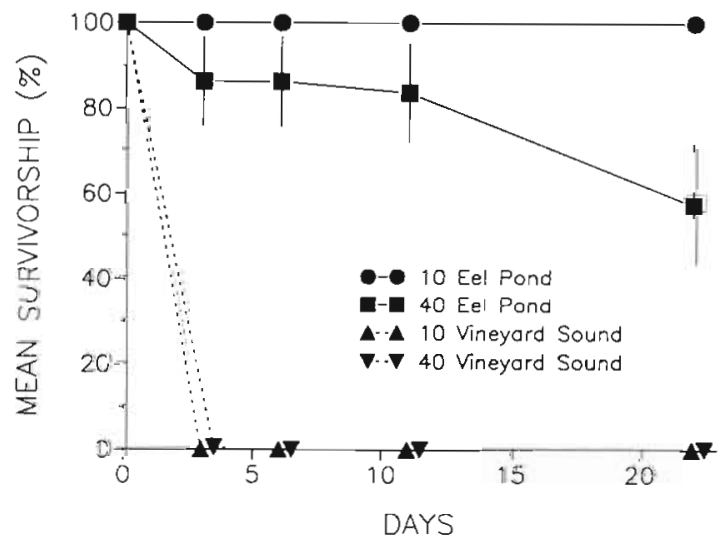

Fig. 5. Botryllus schlosseri. Mean percent survivorship for newly-recruited colonies on panels in Eel Pond and transplanted to Vineyard Sound. Densities were 1.0 and 40 colonies per panel

\section{Predation on recruits}

Recruitment rates of all the species fluctuated throughout the time periods examined and these fluctuations affected the results (Fig. 6). In general, when the recruitment of any species was below 1 ind. $w^{-1}$ on control surfaces no significant differences between control and predator treatments were seen. On the other hand, when recruitment was higher both Anachis avara and Mitrella lunata significantly reduced the recruitment of Botryllus schlosseri. The recruitment rate of Botrylloides diegensis was low throughout the time the studies were conducted and its recruitment was not significantly reduced by the predators. However, A. avara did reduce the recruitment of another colonial ascidian, Diplosoma sp. a species not found at the Woods Hole sites. No other species were affected significantly by the predators.

Finally, the results of the colonization experiment conducted concurrently with the 7 Anachis avara recruitment experiments in 1990 demonstrate that $A$. avara predation on recruiting ascidians does affect the developing adult community. By the final 2 sampling periods the amount of space occupied by epifaunal invertebrates had stabilized at a mean of $80 \%$ cover of each control surface while only $32 \%$ of the surface area of predator treatments had been colonized (Fig. 7). Control surfaces were dominated by Diplosoma sp., Botryllus schlosseri, Botrylloides diegensis, and the solitary ascidian Molgula manhattensis. Unlike the controls, surfaces exposed to A. avara were dominated by spirorbid worms, the bryozoans Bugula turrita and Cryptosula pallasiana, and Diplosoma sp. Even though Diplosoma sp. was common on surfaces exposed to $A$. avara, its abundance was greatly reduced from that found on paired control surfaces.

\section{DISCUSSION}

Although a strong effect of recruitment on a New England epifaunal community is evident, no one factor completely controls this recruitment. Differences in larval settlement, density-dependent mortality, and species-specific mortality of early life-stages all contribute to the observed variability.

The large differences in the availability of settling larvae between the 2 Woods Hole sites must contribute to differences in recruitment, if for no other reason than these establish the initial conditions. The dominant species, both ascidians and bryozoans, have short-lived larvae that presumably travel short distances between release and settlement (e.g. Grosberg 1987, Davis \& Butler 1989). Therefore, the adult community at each site should influence greatly the relative and absolute abundances of larvae settling. In the short term, many more ascidians would be expected to settle at the Eel Pond site than at the site in Vineyard Sound and it is not clear whether at such settlement densities the predators would be able to remove a sufficient number to influence recruitment. For example, the inability of Mitrella 
Fig. 6. Mean number of recruits in paired control (striped bars) and predator (black bars) treatments for the 6 most common recruiting species: the colonial ascidians Botryllus schlosseri, Botrylloides diegensis, and Diplosoma sp., the colonial bryozoans Bugula turrita and Cryptosula pallasiana, and the polychaete Spirorbis spp. Each pair of bars represents the means ( $\pm S E$ ) for an individual experiment. One Anachis avara experiment was conducted in August 1989 and 7 A. avara and 3 Mitrella lunata experiments were conducted in consecutive $8 \mathrm{~d}$ periods between 27 June and 11 September 1990. The second 1990 A. avara experiment was run for $14 \mathrm{~d}$. Differences between paired control and predator treatments were analyzed in each experiment using a paired $t$-test and results are indicated by: $\cdot p<0.05$, $\cdots p<0.01, \cdots p<0.001$

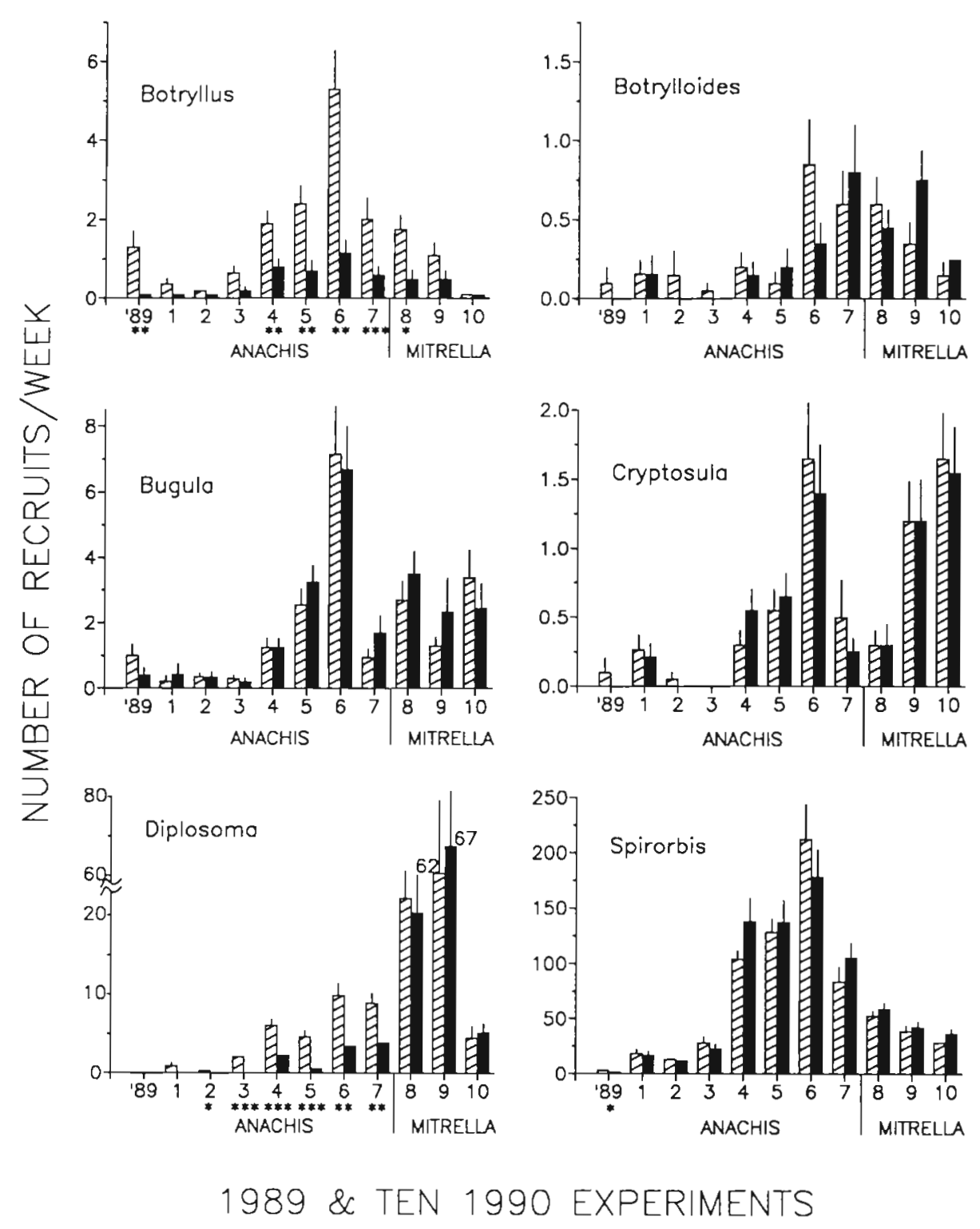

lunata to affect Diplosoma recruitment (Fig. 6) may result from this predator being 'swamped' by an overabundance of ascidian prey. Unfortunately, even though we have observed $M$. lunata preying on Diplosoma sp., we did not conduct any experiments with $M$. lunata when Diplosoma sp. settlement was as low as in the Anachis avara experiments. Likewise, no A. avara experiments were conducted during a time of extremely high Diplosoma sp. settlement and we cannot predict whether the observed levels of Diplosoma sp. settlement during the $M$. lunata experiments would have also swamped A. avara.

On the other hand, the importance of post-settlement predation is indicated by the Vineyard Sound and Groton data. Our experiments demonstrate that without large local populations of ascidians producing huge numbers of settling larvae, gastropod and fish predators are capable of eliminating any recruitment by these species. Stoner (1990) demonstrated that at naturally low densities of settlement, predators can effectively remove all newly-settled individuals within a few days. Our Botryllus schlosseri experiment shows that even when settlement is artificially elevated, the predators at the Vineyard Sound site could remove all new individuals. The Groton experiments illustrate both the ability of predation focused exclusively on newly-settled individuals to alter recruitment and the consequences of this predation as a change of dominance within the developing community.

What is important are the existing conditions at the sites. As long as the micro-predators remain at the Vineyard Sound site, they should be able to prevent 


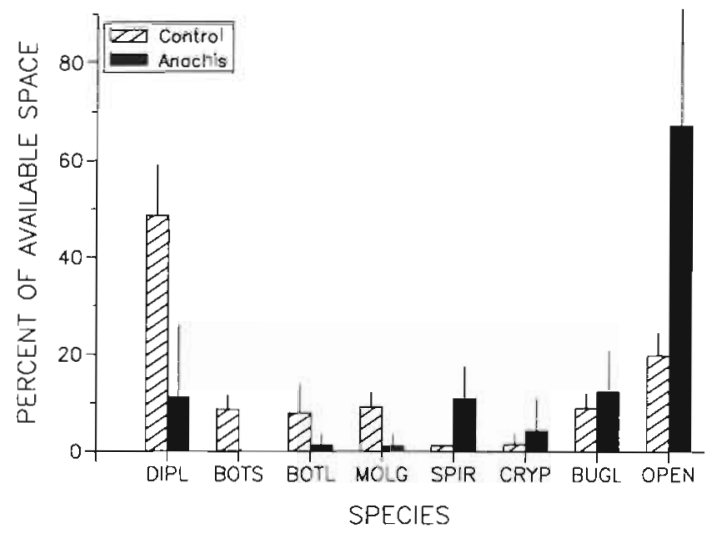

Fig. 7. A comparison of the mean percent cover ( $\pm \mathrm{SE}$ ) of the most abundant species on paired surfaces exposed to predation by a single Anachis avara and control surfaces without any $A$. avara present. The colonization experiment was conducted concurrently with the $1990 \mathrm{~A}$ avara recruitment experiments (Fig. 6) and data were collected after 6 to $8 \mathrm{wk}$ Species shown are: the ascidians Diplosoma sp. (DIPL), Botryllus schlosseri (BOTS), Botrylloides diegensis (BOTL), and Molgula manhattensis (MOLG); the polychaetes Spirorbis spp. (SPIR); the bryozoans Cryptosula pallasiana (CRYP) and Buguia turrita (BUGL); and open space (OPEiv)

the level of recruitment that would allow the establishment of high abundances of ascidians. Conversely, the present high abundance of ascidians in Eel Pond should continue to supply a recruitment rate that would swamp any short-term effect of an invasion by the gastropods. We do not know what past event(s) produced the present distributions of the predators or whether any existing environmental conditions preclude their invasion into Eel Pond. However, we do feel that without the snails preventing recruitment, the colonial ascidians would eventually become more prevalent, if not dominant, at the Vineyard Sound site. The long-term result of any hypothetical invasion of Eel Pond by the snails depends on whether they could ever reach a sufficiently large population size to significantly reduce ascidian recruitment.

Finally, the influence of density-dependent mortality cannot be overlooked, even though it may have been of limited importance within the New England community we were observing. Some densitydependent mortality is indicated by the difference in survivorship between the 2 Botryllus schlosseri density treatments in Eel Pond. However, when compared to the high natural rate of settlement at that site or the strong effects of predation at the Vineyard Sound site, the overall effect of density-dependence may be minimal.

Our data are far from conclusive in contrasting the strengths of the effects of various processes on recruitment. However, the ability of 2 species of tiny gastro- pods, Mitrella lunata and Anachis avara, to influence and, perhaps, control the relative abundances of recruiting species by preying exclusively on newlysettled ascidians is shown. Even though the ascidians are vulnerable to these micro-predators for a very brief period of their life cycle, the predation is sufficiently intense at some sites to eliminate almost all individuals. In areas where these micro-predators are abundant, the competitively superior colonial ascidians are thus prevented from dominating the substrate and this allows other species such as bryozoans to become abundant. Observations of the predation by the wrasse Tautogolabrus adspersus on juveniles of the solitary ascidians Molgula manhattensis, Ciona intestinalis, and Styela clava (Osman et al. 1990) suggest that such selective predation on juvenile life-stages may be quite common within this New England community. Regardless, it is clear that differential mortality among post-settlement juveniles can have as much influence on recruitment as the supply of larvae. In addition, these induced changes in recruitment have a strong effect on the presence of some species within the developing community, and thus the importance or existence of later interactions among adults. That small micro-predators, usually overlooked as unimportant members of the community, can have such an extreme effect on dominance within the community is equally important.

Ultimately, it will be necessary to understand whether ontogenetically changing trophic relationships are common and significant components of the dynamics of marine communities or novel elements of the particular system we have been investigating. Simple modelling (Osman et al. 1990) has shown that predation exclusively on juvenile stages does have the potential to control the abundance of the larger predators within a community by regulating the number of juveniles that survive to become adult prey. In addition, a variety of potential crustacean, molluscan, annelid, and echinoderm micro-predators exists within many marine communities, including the tiny juvenile stages of large, more commonly investigated predators. Most of these will require equally small prey and thus have the potential to affect recruitment (Day \& Osman 1981). Larval supply, recruitment, and adult interactions cannot be isolated from the events occurring among these small, short-lived, early life-stages.

Acknowledgements. We thank L. Springer and H. Zajac for help in the field and laboratory and R. Karlson, S. Gaines, L. Hurd, and an anonymous reviewer for therr comments. This work was supported by a grant from the Jessie B. Cox Charitable Trust and NSF grants OCE-9101815, OCE9123890 . 


\section{LITERATURE CITED}

Barker, M. F. (1979). Breeding and recruitment in a population of the New Zealand starfish Stichaster australis (Verrill). J. exp. mar. Biol. Ecol. 41: 195-211

Bernstein, B. B., Jung, N. (1979). Selective pressures and coevolution in a kelp canopy community in southern California. Ecol. Monogr. 49: 335-355

Caffey, H. M. (1985). Spatial and temporal variation in settlement and recruitment of intertidal barnacles. Ecol. Monogr. 55: 313-332

Connell, J. H. (1985). The consequences of variation in initial settlement vs. post-settlement mortality in rocky intertidal communities. J. exp. mar. Biol. Ecol. 93: 11-45

Davis, A. R., Butler, A. J. (1989). Direct observations of larval. dispersal in the colonial ascidian Podoclavella moluccensis Sluiter: evidence for closed populations. J. exp. mar. Biol. Ecol. 127: 189-203

Day, R. W., Osman, R. W. (1981). Predation by Patiria miniata (Asteroidea) on bryozoans: prey diversity may depend on the mechanism of succession. Oecologia 51: 300-309

Gaines, S. D., Roughgarden, J. (1987). Fish in offshore kelp forests affect recruitment to intertidal barnacle populations. Science 235: 479-481

Grave, B. H. (1933). Rate of growth, age at sexual maturity, and duration of life of certain sessile organisms at Woods Hole, Massachusetts. Biol. Bull. 65: 375-386

Grosberg, R. K. (1981). Competitive ability influences habitat choice in marine invertebrates. Nature, Lond. 290: $700-702$

Grosberg, R. K. (1982). Intertidal zonation of barnacles: the influence of planktonic zonation of larvae on vertical distribution of adults. Ecology 63: 894-899

Grosberg, R. K. (1987). Limited dispersal and proximitydependent mating success in the colonial ascidian Botryllus schlosseri. Evolution 41: 372-384

McGuinness, K. A., Davis, A. R. (1989). Analysis and interpretation of the recruit-settler relationship. J. exp. mar. Biol. Ecol. 134: 197-202

Menge, B. A., Sutherland, J. P. (1987). Community regulation: variation in disturbance, competition, and predation in relation to environmental stress and recruitment. Am. Nat. 130: $730-757$

Osman, R. W. (1977). The establishment and development of a marine epifaunal community. Ecol. Monogr. 47: 37-63

This article was presented by $R$. H. Karlson, Newark, Delaware, USA
Osman, R. W. (1982). Artificial substrates as ecological islands. In: Cairns, J. (ed.) Artificial substrates. Ann Arbor Science Publishers, Inc., Massachusetts, p. 71-114

Osman, R. W., Whitlatch, R. B., Malatesta, R. J., Zajac, R. N (1990). Ontogenetic changes in trophic relationships and their effects on recruitment. In: Barnes, M., Gibson, R. N (eds.) Trophic relationships in the marine environment, Proc. 24th European Mar Biol. Symp. Aberdeen Univ. Press, Scotland, p. 117-129

Osman, R. W., Whitlatch, R. B., Zajac, R. N. (1989). Effect of resident species on recruitment into a community: larval settlement versus post-settlement mortality in the oyster Crassostrea virginica. Mar. Ecol. Prog. Ser. 54: 61-73

Roughgarden, J., Gaines, S., Possingham, H. (1988). Recruitment dynamics in complex life cycles. Science 241: $1460-1466$

Roughgarden, J., Iwasa, Y., Baxter, C. (1985). Demographic theory for an open marine population with space-limited recruitment. Ecology 66: 54-67

Stoner, D. S. (1990). Recruitment of a tropical colonial ascidian: relative importance of pre-settlement and postsettlement processes. Ecology 71: 1682-1690

Sutherland, J. P. (1974). Multiple stable points in natural communities. Am. Nat. 108: 859-873

Underwood, A. J., Denley, E. J. (1984). Paradigms, explanations and generalizations in models for the structure of intertidal communities on rocky shores. In: Strong. D. R. Jr, Simberloff, S., Abele, L. G., Thistle, A. B. (eds.) Ecological communities: conceptual issues and the evidence. Princeton Univ. Press, New Jersey, p. 151-180

Wethey, D. S. (1984). Spatial pattern in barnacle settlement: day to day changes during the settlement season. J. mar. Biol. Ass. U.K. 64:687-698

Wethey, D. S. (1986). Local and regional variation in settlement and survival in the littoral barnacle Semibalanus balanoides (L.): patterns and consequences. In: Moore, P. G., Seed, R. (eds.) The ecology of rocky coasts. Columbia Univ. Press, New York, p. 194-202

Yoshioka, P. M. (1982). Role of planktonic and benthic factors in the population dynamics of the bryozoan Membranipora membranacea. Ecology 63: 457-468

Young, C. M., Chia, F. S. (1984). Microhabitat-associated variability in survival and growth of subtidal solitary ascidians during the first 21 days after settlement. Mar. Biol. 81: $61-68$

Manuscript first received: October 18, 1991 Revised version accepted: April 24, 1992 